\title{
ARTIGOS
}

\section{CARACTERÍSTICAS EPIDEMIOLÓGICAS DA LEISHMANIOSE TEGUMENTAR AMERICANA EM UMA REGIÃO ENDÊMICA DO ESTADO DA BAHIA. II LEISHMANIOSE CANINA}

\author{
Air C. Barretto, Cesar Cuba Cuba, Júlio A. Vexenat, \\ Ana C. Rosa, Philip D. Marsden e Albino V. Magalhães
}

\begin{abstract}
Um inquérito em cães realizado na região de Três Braços, Bahia, mostrou que 3,0\% de 98 animais tinham amastigotas em lesões de pele. Parasitos não foram encontrados em pele normal da orelha. De uma amostra selecionada de 13 cães, portadores de lesão cutânea ativa, nove $(69,2 \%)$ deles estavam comprovadamente infectados. Sete amostras de lesão produziram infecção em hamsters. O estudo biológico (crescimento em meio de cultura, evolução da lesão em hamster e desenvolvimento no tubo digestivo de Lutzomyia longipalpis) identificou o parasito como pertencente ao complexo $\mathrm{L}$. braziliensis. $A$ caracterização bioquímica (mobilidade eletroforética de enzimas em placas de acetato de celulose) e o estudo imunotaxonómico (anticorpos monoclonais) definiram as amostras como L. braziliensis braziliensis.

O papel do cão como um possível reservatório de L. b. braziliensis na regiào de Três Braços é discutido.
\end{abstract}

Palavras chaves: Leishmaniose canina. L. braziliensis braziliensis. Caracterização de cepas. Epidemiologia.

Desde o trabalho de Pedroso 26 , há 70 anos, ate os dias atuais, o achado de parasitos do gênero Leishmania em lesões cutâneas de cães de áreas endêmicas de leishmaniose tegumentar tem sido relatado, com freqüencia, em vários paises do continente 6891019202122262728293031 . Entretanto, o papel desse animal como um possivel reservatório dessas Leishmanias dermotrópicas nunca foi esclarecido. $\mathrm{Na}$ realidade, nem mesmo o parasito era adequadamente identificado devido, principalmente, à pobreza de conhecimentos sobre as várias espécies e subespécies de Leishmania. Somente após trabalhos recentes definindo os Complexos de Leishmania e suas subespécies, pelo emprego de modernas técnicas que permitem a separação desses parasitos, através de suas características biológicas ${ }^{12} 13$, bioquímicas 112425 e imunológicas 23 , novos campos foram abertos para um melhor conhecimento taxonòmico desses flagelados e um melhor entendimento da ecologia e epidemiologia das leishmanioses.

Trabalho realizado com o auxilio financeiro do Conselho Nacional de Desenvolvimento Científico e Tecnológico (CNPq) 403690/82 U.S. Public Health Service AI 16282 e Ministério da Saúde (SUCAM).

Endereço para correspondência: Faculdade de Ciências da Saúde - Núcleo de Medicina Tropical e Nutrição, Universidade de Brasília, Brasília, DF - 70910 - Brasil.

Recebido para publicação em 9/3/84.
Muito recentemente, trabalhos preliminares apresentados em Congresso mostraram, pela primeira vez, que parasitos isolados de lesões de cão provenientes da Bahia ${ }^{34}$, Rio de Janeiro ${ }^{17}$ e Venezuela 1 foram caracterizados bioquimicamente como Leishmania braziliensis braziliensis.

A presença de cães portadores de extensas lesões cutâneas em uma área endêmica de leishmaniose tegumentar (Três Braços, Bahia) levou-nos à realização deste trabalho, visando a determinação da prevalência de infecção nesse animal e a identificação do maior número possível de amostras isoladas de lesōes.

\section{MATERIAL E MÉTODOS}

Inicialmente foi realizado um inquérito em cães, preliminar, casa/casa na vila de Três Braços e fazendas adjacentes. Essa região, endêmica de leishmaniose tegumentar, está localizada nos municipios de Cravolândia, Ubaíra e Wenceslau Guimarães no Estado

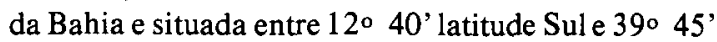
longitude Oeste. Foram examinados 98 cães, dos quais era retirado um fragmento da ponta da orelha ou da borda da lesão, quando existente, para confecção de esfregaços. Amostras de sangue foram coletadas em papel de filtro para a realização de reação de fixação de complemento (RFC') para calazar. 
Barreto AC, Cuba CC, Vexenat JA, Rosa AC, Marsden PD, Magalhães AV. Caracteristicas epidemiológicas da leishmaniose tegumentar americana em uma região endêmica do estado da Bahia. II Leishmaniose canina. Revista da Sociedade Brasileira de Medicina Tropical 17: 59-65, Abr-Jun, 1984

Posteriormente, treze cães portadores de lesão ativa, suspeitos de leishmaniose foram selecionados para o segundo objetivo deste trabalho. A lesão era cuidadosamente lavada com salina a $0,8 \%$ e duas amostras eram retiradas. Um dos fragmentos era colocado em formol-zenker para estudo histopatológico. A segunda amostra era destinada à feitura de esfregaços por aposição e, logo após, triturada com salina e inoculada em focinho e patas de um hamster. A tentativa de isolamento primário através de meio de cultura foi evitado devido à constante contaminação por fungos. Os hamsters inoculados eram observados até um periodo máximo de um ano. Quando havia suspeita de infecção, pelo aparecimento de lesão cutânea ou emagrecimento progressivo do animal, característica de visceralização de parasitos isolados nessa área, material de pele e/ou vísceras (baço, figado) eram retirados para confecção de esfregaços, isolamento em meios de cultura (NNN, LIT, Agar Sangue Difco ${ }^{33}$ ) e subinoculações em novos hamsters. Criopreservação dos isolados era também realizada.

Uma vez obtida a infecção em hamster, exemplares de Lutzomyia longipalpis, provenientes da colònia mantida em nosso laboratório, eram alimentados nas lesões cutâneas, utilizando-se um aparelho simples idealizado por Vexenat ${ }^{32}$. Os insetos eram dissecados após a oviposição (4 a 5 dias depois do repasto), com a finalidade de observar o padrão de desenvolvimento do parasito no tubo digestivo (Lainson e cols. ${ }^{14} 15$ ).

A caracterização bioquímica dos isolados foi realizada a partir de formas de cultura, com as quais foram preparados os lisados. $O$ estudo eletroforético foi feito em placas de acetato de celulose, e o padrão isoenzimático foi determinado com as enzimas ALAT, ASAT, G6PD e ACP (Laboratório de Microbiologia e Imunologia da Universidade de Brasilia - Prof. Isaac Roitman).

Uma bateria de sete anticorpos monoclonais espécie e subespécie específicos para L. braziliensis e L. mexicana foi empregada para a análise de sete estoques isolados de cães, através da técnica de imunofluorescência indireta (IFI). Os clones utilizados foram: VI 4B9D10, XIII 3F4F6, XIII 3E6B1 1, IX 1F9D8, XIII 2A5A10, LXVII 1D7B8 e LXVIII 4E12D8, sendo um especifico para $L$. braziliensis, três subespecificos para $L$. b. braziliensis, um para $L$. $m$. amazonensis e dois para $L$. m. mexicana. Os anticorpos monoclonais de $L$. mexicana foram diluídos a 1:1.000 e os de L. braziliensis, 1:100. O anti- geno empregado foi promastigotas cultivados em meio de Schneider adicionado com $20 \%$ de soro bovino fetal e citocentrifugado em lâminas de microscópio (Citocentrifuga Shandon Cytospin). $O$ conjugado fluorescente (coelho) IgG anti-camundongo $F$ abl 2 (Cappel Laboratories) foi usado a uma diluição 1:20. As amostras utilizadas como controle foram LTB-363 (L. b. braziliensis) L. 3. (L. mexicana amazonensis). A leitura foi realizada empregando-se uma escala arbitrária. Positividade: uma cruz $(+)$ a três $(+++)$. A fluorescência de membranas e flagelos foi também considerada. Negatividade: os organismos apresentavam-se sem brilho e de cor vermelha na luz ultravioleta.

\section{RESULTADOS}

De 98 cães examinados durante o inquérito preliminar, três $(3, \%)$ mostraram amastigotas em esfregaço de lesão cutânea. As lesões variaram desde pequenas, com bordas regulares, até aquelas extensas e mutilantes e que se localizavam em toda a orelha do animal (Fig. 1). Não foram encontrados parasitos em pele normal e a reação sorológica para calazar foi negativa para todas as amostras, inclusive para os cães, portadores da doença.

De treze cães selecionados, portadores de lesões ativas no focinho, orelhas ou patas, suspeitas de leishmaniose, nove $(69,2 \%)$ estavam comprovadamente infectados com parasitos do gênero Leishmania. Apenas três mostraram raros amastigotas em esfregaços de lesão e sete, incluindo dois positivos por esfregaço, produziram infecção em hamster. De um outro cão, a amostra foi isolada aiıavés de meio de cultura e as formas promastigotas não infectaram hamster (Tabela 1). As lesões de patas ou focinho dos hamsters infectados tiveram crescimento lento e relativamente poucas formas amastigotas em esfregaçouma das características do complexo L. braziliensis. Todas as amostras que infectaram hamsters e cujos animais sobreviveram um maior período de tempo produziram visceralização. Em duas amostras foi verificado apenas visceralização, sem lesão cutânea. Em nenhum caso houve metástase, como ocorre freqüentemente com parasitos do complexo $L$. mexicana (Tabela 1).

Nenhum dos isolados cresceu em meio LIT, porém, todos cresceram de modo discreto em NNN e relativamente abundante em Difco Agar Sangue (Tabela 1). Também, quando cultivados em meio de Schneider (Schneider's Drosophila Medium) com a finalidade de preparação do antígeno, o parasito cresceu de forma abundante. 
Barreto AC, Cuba CC, Vexenat JA, Rosa AC, Marsden PD, Magalhães AV. Características epidemiológicas da leishmaniose tegumentar americana em uma regiâo endêmica do estado da Bahia. II Leishmaniose canina. Revista da Sociedade Brasileira de Medicina Tropical 17: 59-65, Abr-Jun, 1984

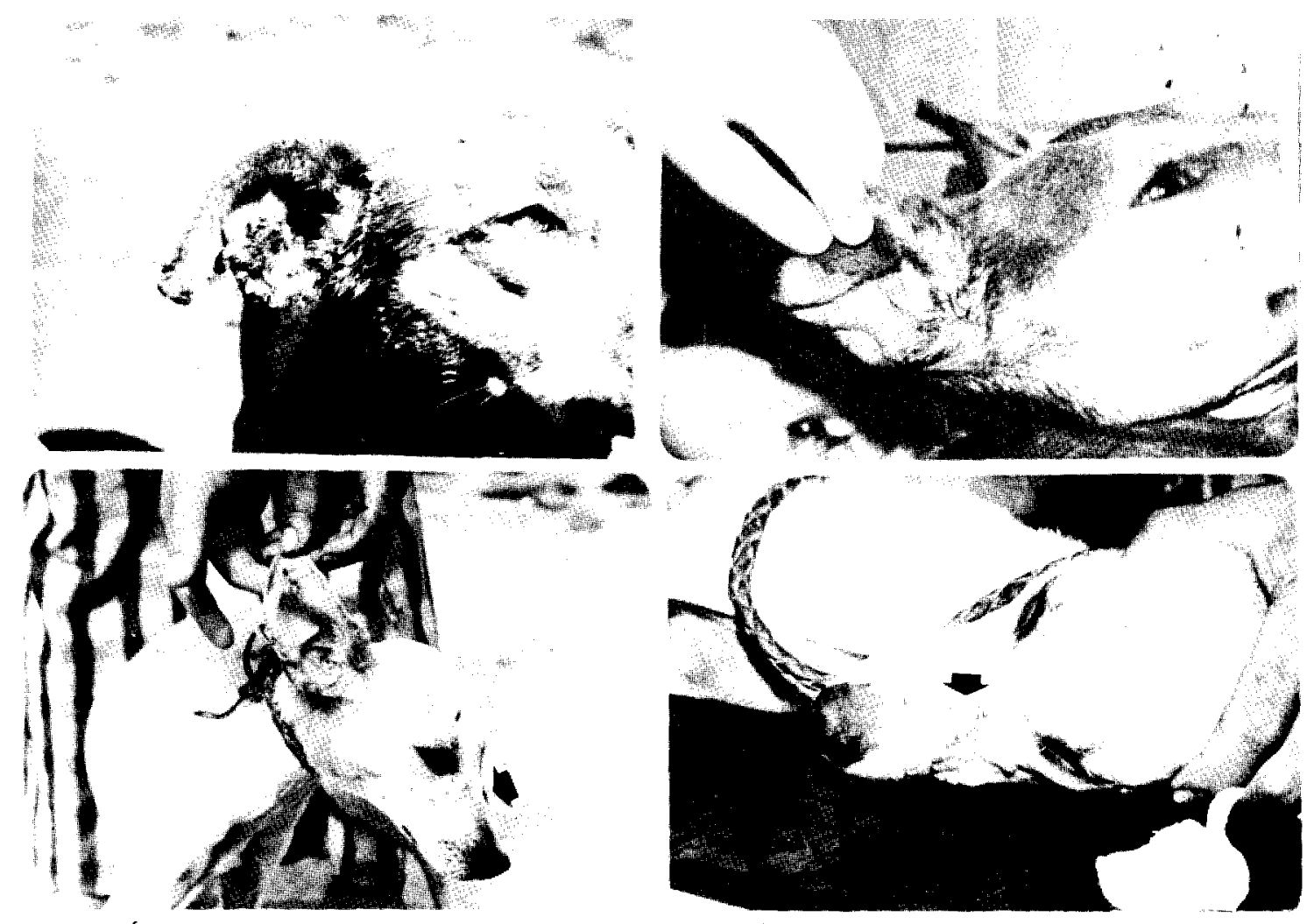

Figura 1 - Úlceras leishmanióticas em cães naturalmente infectados com Leishmania braziliensis braziliensis.

Tabela I-Caracterização biológica e bioquímica de amostras de Leishmania isoladas de lesões cutâneas de cães da região de Três Braços, Bahia

\begin{tabular}{|c|c|c|c|c|c|}
\hline \multirow[b]{2}{*}{ Amostras esfregaço } & \multicolumn{4}{|c|}{ Comportamento das amostras } & Identificaçāo \\
\hline & Meio de cultura & & Hamster & Tubo digestivo & Isoet \\
\hline
\end{tabular}

\begin{tabular}{|c|c|c|c|c|c|c|c|c|c|c|}
\hline CTB- 17 & + & - & - & - & + & - & + & - & Peripilário ( $1 / 46)$ & L. b. braziliensis \\
\hline СТВ-25 & + & - & $+t$ & $++t$ & + & - & + & - & Peripilário ( $3 / 04)$ & L. b. braziliensis \\
\hline CTB-31 & - & - & ++ & $+t+$ & + & - & + & - & Peripilario ( $7 / 13)$ & L. b. braziliensis \\
\hline СТВ-39 & - & - & ++ & +++ & + & - & + & - & Peripilário ( $1 / 05)$ & L. b. braziliensis \\
\hline CTB-ITA & + & & NF & & NF & & NF & & $\mathrm{NF}$ & NF \\
\hline CTB-49 & - & - & ++ & +++ & + & - & + & - & Peripilário $(20 / 22)$ & L. b. braziliensis \\
\hline CTB-52 & - & - & ++ & +++ & + & - & + & - & $-(0 / 02)$ & L. b. braziliensis \\
\hline СТВ-142 & - & - & ++ & +++ & + & - & $\mathbf{M}^{*}$ & - & Peripilário ( $2 / 05)$ & $\mathrm{NF}$ \\
\hline CTB- 147 & NF & - & ++ & +++ & ** & & & & NF & NF \\
\hline
\end{tabular}

* O hamster morreu, não se observando metástase ou visceralização.

** Isolamento primário em meio de cultura, promastigotas não infectaram hamster.

*** Perfil enzimático indistinguivel da amostra padrão M2904 (L. b. braziliensis).

NF Não feito. 
Barreto AC, Cuba CC, Vexenat JA, Rosa AC, Marsden PD, Magalhães AV. Características epidemiológicas da leishmaniose tegumentar americana em uma região endêmica do estado da Bahia. II Leishmaniose canina. Revista da Sociedade Brasileira de Medicina Tropical 17: 59-65, Abr-Jun, 1984

Tabela 2 - Reatividade de promastigotas de amostras de Leishmania isoladas de cães de Três Braços, Bahia. Brasil, a anticorpos monoclonais testados pela imunofluorescência indireta.

\begin{tabular}{|c|c|c|c|c|c|c|c|c|c|c|c|}
\hline \multicolumn{2}{|c|}{ Código do Clone* } & \multirow[t]{2}{*}{ Especificidade } & \multicolumn{9}{|c|}{ Amostras de Leishmania } \\
\hline & & & \multicolumn{4}{|c|}{ СТВ-17 СТВ-25 СТВ-31 CТВ-39 } & CTB -49 & CTB-142 & \multicolumn{2}{|c|}{ CTB-147 LTB-363** } & \multirow{2}{*}{$\frac{\mathrm{L}-3^{* * *}}{-}$} \\
\hline VI & 4B9D10 & L. braziliensis & ++ & ++ & +++ & + & +++ & +++ & + & ++ & \\
\hline XIII & $3 F 4 F 6$ & L. b. braziliensis & + & + & + & ++ & ++ & $++t$ & ++ & ++ & - \\
\hline XIII & $3 \mathrm{E} 6 \mathrm{~B} 11$ & L. b. braziliensis & $+t+$ & $+t$ & +++ & $+t$ & +++ & $+t$ & $++t$ & $+t+$ & - \\
\hline XIII & $2 \mathrm{~A} 5 \mathrm{Al} 10$ & L. b. braziliensis & +++ & $+t$ & ++ & $+t$ & +++ & +++ & +++ & $+t$ & - \\
\hline IX & 1F9D8 & L. m. amazonensis & $s \quad-$ & - & - & - & - & - & - & - & $+t+$ \\
\hline LXVII & 1D7B8 & L. $m$ mexicana & - & - & - & - & - & - & - & - & $++t$ \\
\hline LXVIII & $4 \mathrm{E} 12 \mathrm{D} 8$ & L. m. mexicana & - & - & - & - & - & - & - & - & - \\
\hline
\end{tabular}

* Ver McMahon Prat e David 23 .

** Controle: amostra humana de L. b. braziliensis

*** Controle: amostra humana de L. m. amazonensis (Josefa).

Seis dos isolados que produziram infecção em hamster tiveram comportamento tipo peripilário em Lu. longipalpis, isto é: os flagelados cresceram no triângulo posterior do tubo digestivo do inseto. Um dos isolados não infectou os insetos e em dois essa pesquisa não foi realizada (Tabela 1 ).

O quadro histopatológico das lesões de cães consistiu basicamente de infiltrados histolinfoplasmocitários com ausência de amastigotas, semelhante ao que ocorre em lesões de pacientes da área de estudo.

O padrão isoenzimático de seis amostras foi indistinguivel da amostra padrão M2904 (L. b. braziliensis) (Tabela 1).

As amostras CTB-17, CTB-25, CTB-31, CTB-39, CTB-52, CTB-142 e CTB-147 isoladas de cães e a amostra LTB-363 (L. b. braziliensis), de origem humana, usada como controle, reagiram positivamente aos anticorpos monoclonais espécie e subespecíficos de $L$. braziliensis, não cruzando com aqueles de L. mexicana. A amostra L.3 (L. m. amazonensis), de origem humana, também usada como controle, teve um procedimento inverso. Um dos anticorpos monoclonais de $L$. m. mexicana falhou em reagir com qualquer amostra (Tabela 2 ).

\section{DISCUSSÃO}

Todas as amostras isoladas de lesões ativas de cães da região de Três Braços tiveram o mesmo comportamento biológico, bioquímico e imunológico. O crescimento pobre em meio de cultura NNN e a evolução lenta das lesões cutâneas, sem a formação de histiocitomas, sugeriram a identificação do parasito como pertencente ao complexo $L$. braziliensis. A visceralização de todas as amostras em hamsters foi uma constante, semelhante ao que ocorre com amostras de origem humana da área $\left(\mathrm{Cuba}^{5}\right.$ e Cuba e cols $\left.{ }^{4}\right)$. Este fato foi tambèm assinalado por Dias e col. ${ }^{6}$, com Leishmania isolada de cães da área de Caratinga e não foi mencionado por Lainson e Shaw 1315 nos seus estudos sobre $L$. braziliensis braziliensis de origem humana.

O desenvolvimento tipo peripilário das amostras no tubo digestivo de $\mathrm{Lu}$. longipalpis confirmou a identificação desse flagelado como pertencente ao Complexo L. braziliensis. Essa técnica, demonstrou ser de grande valia na separação dos complexos L. $m e-$ xicana e L. braziliensis.

O estudo bioquímico de seis amostras definiu a identificação do parasito como sendo $L . b$. braziliensis, semelhante ao parasito isolado de lesões cutâneas e mucosas do homem da região ${ }^{45}$. O padrão isoenzimático mostrou-se indistinguivel da amostra M2904 ( $L . b$. braziliensis). O estudo eletroforético das amostras em placas de acetato de celulose, utilizando-se apenas quatro enzimas (De Sá e col. ${ }^{7}$ ), parece satisfatório para distinção dos complexos L. braziliensis e L. mexicana (ALAT e ASAT) e para a separação das subespécies $L$. $b$. braziliensis e L. b. guyanensis (G6PD) e L. m. amazonensis e L. m. mexicana (ACP).

O emprego de anticorpos monoclonais para a caracterização de Leishmania isolada de cães foi realizada anteriormente por $\mathrm{Cuba}^{5}$. $\mathrm{O}$ autor utilizou a técnica de radioimunoensaio e de imunofluorescên- 
Barreto AC, Cuba CC, Vexenat JA, Rosa AC, Marsden PD, Magalhães AV. Características epidemiológicas da leishmaniose tegumentar americana em uma região endêmica do estado da Bahia. II Leishmaniose canina. Revista da Sociedade Brasileira de Medicina Tropical 17: 59-65, Abr-Jun, 1984

cia e identificaram a amostra $\mathrm{C}-25(=\mathrm{CTB}-25)$ de Três Braços, como L. b. braziliensis. Também Marzochi e col. 18 , recentemente,. identificaram como L. b. braziliensis um parasito isolado de gânglio linfático de um cão que não apresentava lesão cutânea, proveniente de uma área endêmica de leishmaniose visceral e tegumentar. As sete amostras, isoladas de lesões cutâneas de cães da região de Três Braços, Bahia, foram confirmadas como $L . b$. braziliensis, empregando-se uma bateria de anticorpos monoclonais espécie e subespécie específicos de $L$. braziliensis e $L$. mexicana, como reagentes da técnica de imunofluorescência indireta (Tabela 2).

$\mathrm{Na}$ região de Três Braços, Bahia, Brasil, endêmica de leishmaniose tegumentar americana, cujas principais características foram publicadas anteriormente ${ }^{2}$, o parasito altamente predominante no homem é a $L$. b. braziliensis, de acordo com os estudos biológicos, bioquímicos e de imunotaxonomia 45 . Em mais de 300 casos de leishmaniose humana verificados na região nestes últimos oito anos de trabalhos ininterruptos, nenhum paciente de calazar foi observado. Reservatórios primários de $L$. braziliensis na região ainda não foram identificados a despeito de mais de 600 animais silvestres terem sido examinados. Apenas três roedores (Proechymis inhering denigratus) foram encontrados infectados com $L$. mexicana sp (dados não publicados). O cão é encontrado com lesões cutâneas, às vezes extensas, principalmente nas orelhas e focinho, sendo RFC' negativa para calazar. A histopatologia das lesões é compatível com aquela observada em lesões humanas produzidas por $L$. b. braziliensis. O inquérito canino realizado na área mostrou uma prevalência baixa de cães infectados $(3,0 \%)$, mas quando uma amostra de animais, portadores de lesões, foi selecionada, o indice de positividade foi bastante elevado, semelhante ao que ocorreu em Caratinga ${ }^{6}$. Na região de Três Braços, o cão é utilizado na caça, principalmente de pacas e tatus e, em uma mesma residència, o cão e o homem, inclusive crianças que nào freqüentam a mata, podem ser encontrados com lesões leishmanióticas.

Para alguns autores 1622 , o cão é apenas um hospedeiro circunstancial, ou vítima tal qual o homem. $\mathrm{Na}$ realidade, se por um lado ainda não existem dados concretos para incriminar esse animal como um reservatório secundário de $L . b$. braziliensis, provas que permitam descartar o seu papel na epidemiologia da doença também ainda não forám conseguidas.

Acreditamos, entretanto, de acordo com os conhecimentos atuais, que o cão possa ter alguma importância como reservatório secundário de L. b. braziliensis em Três Braços. As evidências são: 1) o parasito circulando no homem e no cão na região se comportam como L. b. braziliensis; 2 ) crianças que não freqüentam a mâta adquirem a doença, aparentemente, em suas casas; 3 ) animais que freqüentam o peridomicílio (Rattus rattus, Didelphis) não têm sido encontrados infectados; 4) Lu. whitmani, altamente predominante no domicilio e seus arredores, é antropofilico, sendo também atraído pelo cão; 5) essa espécie de flebotomineo, oriundo da região e criado em laboratório, infecta-se experimentalmente em lesões de cães parasitados com $L$. $b$. braziliensis de origem canina, também da região.

\section{SUMMARY}

During a survey of domestic and hunting dogs conducted in the Trés Bracos region, State of Bahia, 3,0\% of 98 dogs had amastigotes in skin lesions. Parasites were not found in normal ear skin. In a nonrandomly selected sample of 13 dogs with active cutaneous lesions, infection was confirmed in nine $(69,2 \%)$. Tissue biopsies from seven dog lesions produced infection in hamsters. The biological behaviour of the parasite (rate of growth in culture media, evolution of lesions in hamsters and development in the gut of Lutzomyia longipalpis) identified it to the Leishmania braziliensis complex. Characterization by biochemical means (eletrophoretic mobility of enzymes in cellulose acetate plates) and immunotaxonomic studies (monoclonal antibodies) defined the strains as L. braziliensis braziliensis.

The role of dogs as a possible reservoir host of L. b. braziliensis in Três Braços region is discussed.

Key words: Canine Leishmaniasis. L. braziliensis braziliensis. Strain Characterization. Epidemiology.

\section{REFERÊNCIAS BIBLIOGRÁFICAS}

1. Aguillar CM, Momen H, Grimaldi G, Deane LM. Leishmania braziliensis braziliensis in donkeys (Equus asinus) in central Venezuela. In: Resumos da IX Reunião Anual Pesquisa básica em doenças de Chagas, (comunicação 129), Caxambu, Minas Gerais, p. 106, 1982.

2. Barretto AC, Cuba Cuba C, Marsden PD, Vexenat JA, De Belder M. Caracteristicas epidemiológicas da 
Barreto AC, Cuba CC, Vexenat JA, Rosa AC, Marsden PD, Magalhães AV. Caracteristicas epidemiológicas da leishmantose tegumentar americana em uma região endêmica do estado da Bahia. II Leishmaniose canina. Revista da Sociedade Brasileira de Medicina Tropical 17: 59-65, Abr-Jun, 1984

leishmaniose tegumentar americana em uma região endèmica do Estado da Bahia. Brasil. I Leishmaniose humana. Boletin de la Oficina Sanitária Panamericana 90: 415-424, 1982.

3. Barretto AC, Cuba Cuba C, Marsden PD, Vexenat JA, Magalhães AV. Identificação de Leishmania braziliensis braziliensis em cães naturalmente infectados em uma região endêmica de leishmaniose cutânea-mucosa. In: Resumos da IX Reunião Anual Pesquisa básica em doença de Chagas, (comunicação 135), Caxambu, Minas Gerais, p. 109, 1982.

4. Cuba CAC, Miles M, Vexenat JA, Marsden PD, Barretto $\mathrm{AC}$, Jones $\mathrm{AC}$. Biological and isoenzyme identification of Leishmania stocks from patients and dogs with American Mucocutaneous leishmaniasis. In: Resumos da IX Reunião Anual Pesquisa básica em doença de Chagas, (comunicação n. 97), Caxambu, Minas Gerais, p. 89, 1982.

5. Cuba CAC. Leishmaniose tegumentar em área endêmica do Estado da Bahia, Brasil. Caracterização e classificação de Leishmania do homem e do cão doméstico e aspectos comportamentais de $L$. braziliensis braziliensis. Tese de Doutorado, Universidade Federal de Minas Gerais, Belo Horizonte, 1983.

6. Dias M, Mayrink W, Deane LM, Costa CA, Magalhães P, Melo MN, Batista SM, Araújo FG, Coelho MV, Williams P. Epidemiologia da leishmaniose tegumentar americana I. Estudo de reservatórios em área endèmica no Estado de Minas Gerais. Revista do Instituto de Medicina Tropical de São Paulo 19: 403-410, 1977.

7. De Sá MHP, Lima LMP, Roitman I. The identification of Leishmania by isoenzymes In: Resumos da IX Reuniāo Anual Pesquisa básica em doenças de Chagas (comunicação n. 99), Caxambu, Minas Gerais, p. 90, 1982.

8. Herrer A. Nota preliminar sobre leishmaniasis natural en perros. Revista de Medicina Experimental (Lima) 7: 6269,1948

9. Herrer A. Estudios sobre leishmaniasis tegumentaria en el Peru. V Leishmaniasis natural en perros procedentes de localidades utógenas. Revista de Medicina Experimental (Lima) 8: 87-118, 1949/51.

10. Herrer A, Christensen HA. Natural cutaneous leishmaniasis among dogs in Panamá. The American Journal of Tropical Medicine and Hygiene 25: 59-63, 1976.

11. Kreutzer RD, Christensen HA. Characterization of Leishmania sp., by isoenzyme electrophoresis. The American Journal of Tropical Medicine and Hygiene 29: 199-208, 1980.
12. Lainson $R$, Shaw JJ. Leishmania and leishmaniasis of the New World: taxonomic problems. British Medical Bulletin 28: 44-48, 1972.

13. Lainson $R$, Shaw JJ. Leishmania and leishmaniasis of the New World with particular reference to Brazil. Bulletin of the Pan American Health Organization 7: 1-19, 1973.

14. Lainson R, Ward RD, Shaw JJ. Leishmania in flebotomid sandflies. VI. Importance of hindgut development in distinguishing between parasites of the Leishmania mexicana and L. braziliensis complexes. Proceedings of the Royal Society, London. 199: 309-320, 1977.

15. Lainson R, Shaw JJ. The role of animals in epidemiology of South America Leishmaniasis. In: Lumsden, WHR \& Evans, DA (eds) Biology of the Kinetoplastida. VII. London and New York. Academic Press pp. 1-116, 1979.

16. Lainson $R$. Leishmanial parasites of mammals in relation to human disease. Symposium Zoology, London 50: 137-179, 1982.

17. Marzochi MCA, Souza WJS, Coutinho SG, Toledo LM, Grimaldi G, Momen H. Evaluation of diagnostic criteria in human and canine mucocutaneous leishmaniasis in a Rio de Janeiro district where Leishmania braziliensis occurs. In: Resumos da IX Reuniāo Anual Pesquisa básica em doença de Chagas, (comunicação n. 46) Caxambu, Minas Gerais, p. 63, 1982.

18. Marzochi MCA, Grimaldi Jr G, Momen H, McMahon Pratt D. Visceral Leishmania braziliensis braziliensis in a dog in Rio de Janeiro (Brazil) In: Resumos da X Reunião Anual Pesquisa básica em doença de Chagas, (comunicação BI 30) Caxambu, Minas Gerais, pp. 3-15, 1983.

19. Mazza S. Existencia de la leishmaniasis cutanea en el perro en la Republica Argentina. Boletin del Instituto de Clinica y Quirurgia (Buenos Aires) 2: 147-149, 1926.

20. Mazza S. Leishmaniasis tegumentaria visceral. Boletin del Instituto de Clinica y Quirurgia (Buenos Aires) 2: 209-216, 1926.

21. Mazza S. Leishmaniasis cutanea en el caballo y nueva observación de la misma en el perro. Boletin del Instituto de Clinica y Quirurgia (Buenos Aires) 3: 462-464, 1927.

22. Mayrink W, Williams $P$, Coelho MV, Dias $M$, Vianna Martins SA, Magalhães P, Costa CA, Falcão AR, Melo MN, Falcão AL. Epidemiology of dermal leishmaniasis in the Rio Doce Valley, State of Minas Gerais, Brazil. Annals of Tropical Medicine and Parasitology 73: 123137, 1979. 
Barreto AC, Cuba CC, Vexenat JA, Rosa AC, Marsden PD, Magalhães AV. Caracteristicas epidemiológicas da leishmaniose tegumentar americana em uma região endêmica do estado da Bahia. II Leishmaniose canina. Revista da Sociedade Brasileira de Medicina Tropical 17: 59-65, Abr-Jun, 1984

23. McMahon Pratt D, David JR. Monoclonal antibodies that distinguish between New World species of Leishmania. Nature 291: 581-583, 1981.

24. Miles MA, Povoa M, Souza AA, Lainson R, Shaw JJ. Some methods for enzymic characterization of Latin American Leishmania, with particular reference to Leishmania mexicana amazonensis and sub-species of Leishmania hertigi. Transactions of the Royal Society of Tropical Medicine and Hygiene 74: 243-252, 1980.

25. Miles MA, Lainson R, Shaw JJ, Povoa M, Souza AA. Leishmaniasis in Brazil. XV. Biochemical distinction of Leishmania mexicana amazonensis, $L$. braziliensis braziliensis and $L$. braziliensis guyanensis aetiological agents of cutaneous leishmaniasis in the Amazon Basin of Brazil. Transactions of the Royal Society of Tropical Medicine and Hygiene 75: 524-529, 1981.

26. Pedroso AM. Leishmania local de cão. Annais Paulistas de Medicina e Cirurgia 1: 33-40, 1913.

27. Pedroso AM. Infeç̧ão de cão pela Leishmania tropical. Revista de Medicina de São Paulo 23: 42-45, 1923.

28. Pifano F. La leishmaniasis tegumentaria en el estado Yaracuy, Venezuela. Revista Policlinica (Caracas) 9: 3639-3658, 1940.
29. Pons AR, Londres H. Leishmaniasis tegumentaria americana en el asentamiento campesino de Zipayare. Aspectos epidemiológicos, clínicos e inmunológicos. Su importancia en la Reforma Agraria. Kasmera 3: 5-59, 1968.

30. Romaña C, Najera LM, Conejos M, Abalos JWI. Leishmaniasis tegumentaria en perros de Tucuman. II. Foco doméstico de leishmaniasis. Anales del Instituto de Medicina Regional (Tucuman) 2: 283-292, 1949.

31. Sherlock I, Almeida SP. Notas sobre leishmaniose canina no Estado da Bahia. Revista Brasileira de Malariologia e Doenças Tropicais 21: 535-539, 1969.

32. Vexenat JA, Cuba CC, Llanos EA, Rosa AC, Barretto AC, Marsden PD. Descrição de um dispositivo para coleta, infeç̧ão experimental e manutenção de flebotomineos adultos (Lutzomyia, Diptera, Psychodidae) In: Resumos da IX Reunião Anual Pesquisa básica em doença de Chagas, (comunicação no 230), Caxambu, Minas Gerais, p. 157, 1982.

33. Walton BC, Shaw JJ, Lainson R. Observations on in vitro cultivation of Leishmania braziliensis. Journal of Parasitology 63: 1118-1119, 1977. 